\title{
SETAC Europe Young Scientist LCA award 2019 for P. James Joyce
}

\section{Joost Dewaele ${ }^{1}$}

Received: 23 May 2019 / Accepted: 5 June 2019 /Published online: 25 June 2019

(C) Springer-Verlag GmbH Germany, part of Springer Nature 2019

\begin{abstract}
At the 29th SETAC Europe annual meeting, May 26-30, 2019, Helsinki (Finland), P. James Joyce received the SETAC Europe Young Scientist LCA Award 2019. James is an environmental scientist by formation (University of Cambridge/Imperial College London), and finished his $\mathrm{PhD}$ in 2019 (KTH Institute of Technology, Sweden). His PhD research focused on the environmental considerations related to valorization of Bauxite residue. Herein, James leveraged his deep fundamental understanding of LCA and programming skills to assess the environmental impacts associated with complex valorization pathways.
\end{abstract}

Keywords Award · SETAC

The SETAC Europe LCA Steering Committee recognizes James for his efforts towards broadening the applicability of LCA and life cycle thinking.

James has a deep and broad understanding of LCA and has carried out many full and streamlined LCA's as a product sustainability consultant (independent; ERM-UK) and researcher of KTH Royal Institute of Technology (Sweden), that includes calculation of carbon footprint and labelling (Tesco), calculation of the benefits of waste prevention (Defra/ WRAP), sustainable clothing calculations (WRAP), LCA of electronic products, and investigating the environmental implications from valorization of bauxite residue.

Throughout his work, James has consistently demonstrated strong interest in developing simple-to-use tools and methods to facilitate the use of life cycle approaches by non-experts. This includes spreadsheet-based tools and software using the Python programming language. Two of his software models (lcopt/lcopt-cv) are regarded as highly instrumental in developing LCA foreground models to overcome lack of industrial scale data of processes under development (lab scale), and successfully used in teaching.
In his more recent work, James also demonstrated his ability to advance impact assessment via new characterization methods, to assess the potential human health and ecosystem impacts of naturally occurring radionuclides.

James is the well-deserved winner of the 2019 SETAC Europe Young Scientist LCA Award. With this, we congratulate James with the award, with the work already accomplished, and wish him a successful continuation of his activities in his position of postdoctoral researcher at KTH Royal Institute of Technology, Sweden.

SETAC Europe Young Scientist LCA award, is sponsored by Lenzing AG (https://www.lenzing.com), and Springer Verlag (http://www.springer.com).

Heinz Stichnothe (Chair)/Joost Dewaele (Award Manager) on behalf of the SETAC Europe LCA steering committee

Publisher's note Springer Nature remains neutral with regard to jurisdictional claims in published maps and institutional affiliations.

Joost Dewaele

dewaele.j@pg.com

1 Environmental Stewardship \& Sustainability, Global Product Stewardship, Procter \& Gamble Brussels Innovation Center, Temselaan 100, 1853 Strombeek-Bever, Brussels, Belgium 